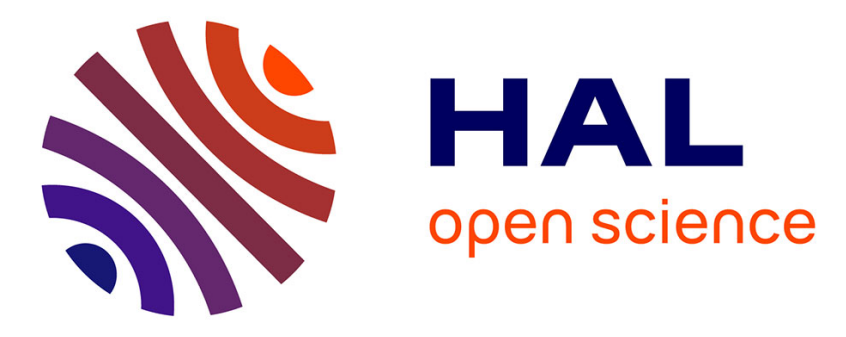

\title{
Evolution of Heterogeneity in Industrial Selective Oxidation Catalyst Pellets
}

\author{
Johannes Ihli, Leonid Bloch, Sebastian Boecklein, Przemyslaw Rzepka, \\ Manfred Burghammer, Julio Cesar da Silva, Gerhard Mestl, Jeroen Anton van \\ Bokhoven
}

\section{To cite this version:}

Johannes Ihli, Leonid Bloch, Sebastian Boecklein, Przemyslaw Rzepka, Manfred Burghammer, et al.. Evolution of Heterogeneity in Industrial Selective Oxidation Catalyst Pellets. ACS Catalysis, 2021, 11 (13), pp.8274 - 8283. 10.1021/acscatal.1c01744 . hal-03349281

\section{HAL Id: hal-03349281 \\ https://hal.science/hal-03349281}

Submitted on 9 Nov 2021

HAL is a multi-disciplinary open access archive for the deposit and dissemination of scientific research documents, whether they are published or not. The documents may come from teaching and research institutions in France or abroad, or from public or private research centers.
L'archive ouverte pluridisciplinaire HAL, est destinée au dépôt et à la diffusion de documents scientifiques de niveau recherche, publiés ou non, émanant des établissements d'enseignement et de recherche français ou étrangers, des laboratoires publics ou privés. 


\section{Evolution of Heterogeneity in Industrial Selective Oxidation Catalyst Pellets}

Johannes Ihli", Leonid Bloch", Sebastian Boecklein ${ }^{\#}$, Przemyslaw Rzepka, Manfred Burghammer, Julio Cesar da Silva, Gerhard Mestl, Jeroen Anton van Bokhoven

Dr Przemyslaw Rzepka, Dr Johannes Ihli and Prof Jeroen Anton van Bokhoven Paul Scherrer Institut, 5232 Villigen PSI, CH

Mr Leonid Bloch, Dr Rzepka Przemyslaw and Prof Jeroen Anton van Bokhoven

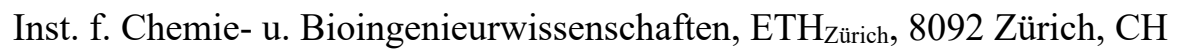

Mr Leonid Bloch and Dr Manfred Burghammer

European Synchrotron Radiation Facility, 38000 Grenoble, FR

Dr Julio Cesar da Silva

Univ. Grenoble Alpes, CNRS, Grenoble INP, Institut Néel, 38000 Grenoble, FR

Dr Sebastian Boecklein and Dr Gerhard Mestl

Clariant AG, Waldheimer Str. 13, 83052 Bruckmühl, Deutschland

\# Equal Contributions

* Correspondence and requests for materials should be addressed to: Gerhard Mestl

(Gerhard.Mestl@clariant.com) and Jeroen van Bokhoven (Jeroen.Vanbokhoven@chem.ethz.ch)

Keywords: Heterogeneous Catalysis; Vanadyl Pyrophosphate; Industrial Catalysis; X-ray Diffraction; X-ray Microscopy 


\begin{abstract}
:
The selective oxidation of $n$-butane over vanadium phosphorus oxides to maleic anhydride is a crucial step in the production of unsaturated polyester resins. As the demand for maleic anhydride is steadily rising, we are urged to develop heterogeneous catalysts of still higher productivity and longer lifetime. To satisfy this demand, we require knowledge of the conversion process on the molecular level, the structure of the catalyst on the nanometre level, e.g. the exposition of active sites in nanoporous and millimetre-sized catalyst bodies or pellets, and an understanding of how these pellets behave within the industrial setting. Here, using scanning X-ray diffraction, we visualize how industrial reactor operation affects commercial porous Raschig-ring-type pellets. The examination of a pristine catalyst pellet and two pellets extracted from an industrial reactor after four years of operation, one from the reactor hot spot zone, revealed a series of structural and compositional modifications that can be linked to decreased catalyst performance and the well-known, low degree of pore utilization, hence, a spatially nonuniform utilization of the catalyst pellets. Specifically, we observe how the suggested differential thermal stress and diffusion limitations induce a radial transformation of the pellets. This process is intensified in the hot spot zone. We hope these observations reiterate the importance of characterizing heterogeneous catalysts at all length scales to contextualize catalyst performance and provide insights that can help to optimize the design of catalyst bodies for the industrial setting.
\end{abstract}




\section{Introduction}

The selective oxidation of $n$-butane $\left(\mathrm{C}_{4} \mathrm{H}_{10}\right)$ over vanadium phosphorus oxides (VPO) to maleic anhydride (MA) $\left(\mathrm{C}_{4} \mathrm{H}_{2} \mathrm{O}_{3}\right)$ is a crucial step in the production of polymers.[1-4] As the production of maleic anhydride[5] is steadily increasing with a current demand of 2 million tons p.a., a plea is present to produce catalysts of increased efficiency. To fulfil such a desire, we require an understanding of the catalyst's structure-property relationship within the context of its industrial setting. Specifically, an understanding of the conversion process on the molecular level,[6] the structure of the catalyst on the nanometre level,[7] i.e. the frequency, density, and accessibility of active sites to the reactive medium in nanoporous and millimetre-sized catalyst bodies, or so-called pellets, and how these catalyst pellets behave within the industrial setting.

On a molecular level, several mechanisms have been suggested for the exothermic selective oxidation of $n$-butane,[6, 8-10] including redox couple mechanisms.[6] These mechanisms suggest a conversion of surfacebound $n$-butane through a series of intermediates to MA. Surface-available redox pairs are considered to separate between $n$-butane activation and the oxidation to MA. It comes as such to no surprise that vanadium phosphorous oxides of increased structural disorder, such as nanoparticles and amorphous solids, possessing a greater density of these pairs, are found in industrial VPO catalysts. [4, 5, 11-20] The dominant oxide is vanadyl pyrophosphate, $(\mathrm{VO})_{2} \mathrm{P}_{2} \mathrm{O}_{7}$, often prepared from vanadyl hydrogenphosphate hydrates $\left(\mathrm{VO}\left(\mathrm{HPO}_{4}\right)\left(\mathrm{H}_{2} \mathrm{O}\right)_{\mathrm{n}}\right) \cdot[5,16,21-23]$

Industrial level conversion is historically carried out in fixed-bed reactors, operated in upward flow configuration at roughly $400^{\circ} \mathrm{C}$. These reactors consist of a series of actively cooled reactor tubes immersed in a molten salt bath and are filled with VPO catalyst pellets. The tubes are fed with preheated mixtures of oxygen, $n$ butane ( $<2$ vol.\%), water $(\sim 3$ vol.\%), and trimethyl phosphate (TMP) $(\sim 1 \mathrm{ppmV})$. [5] The latter two are added to combat catalyst deactivation mechanisms, commonly registered in the form of a decreasing MA yield and selectivity as well as a decreasing phosphorus to vanadium ratio in the catalyst bodies, and to decrease the temperature of the hot-spot formed in the feed entrance region of the reactor tube. The employed pellets themselves are frequently of the porous bulk type, i.e. consist dominantly of catalytic matter with a specific surface area $<50$ $\mathrm{m}^{2} \mathrm{~g}^{-1} \cdot[24,25]$

One of the problems prohibiting process improvement is that these catalysts undergo, yet to be fully understood, compositional and structural changes over years during industrial operation on the $\mathrm{nm}$ and $\mu \mathrm{m}$ level. This not only makes catalyst design optimization challenging but also contributes to a discussion regarding active sites and general reaction mechanisms. In an earlier study, we examined changes on the nanometre-level through means of spectro-tomography on $\mu \mathrm{m}$-sized samples.[7] A change was revealed from a mesoporous pristine catalyst, composed of a series of amorphous and nanocrystalline vanadium phosphate phases, to a macroporous catalyst composed of micron-sized and defect-rich vanadyl pyrophosphate after years of industrial use.

Here, we extend the scope of observation by visualizing reactor operation-induced spatio-chemical heterogeneities across the entire catalyst pellets. This was achieved by cross-sectioning of catalyst pellets extracted from a fixed-bed reactor and their examination using scanning X-ray diffraction.[26] The examination of a pristine catalyst, and two used catalysts, one from the reactor hot spot zone, revealed location-specific phase transformations and microstructural modifications that can be linked to decreasing catalyst performance. Specifically, we observe how the diffusion limitation due to the well-known, low pore utilization leads to differential thermal stress and, hence, in turn to a spatially non-uniform utilization of the catalyst pellets which 
induces a radial restructuring of the catalyst pellet.[27] This process appears intensified in the hot spot zone, exemplified by, an increased amorphization of the catalytically active $(\mathrm{VO})_{2} \mathrm{P}_{2} \mathrm{O}_{7}$. 


\section{Bulk Characterisation of Vanadium Phosphorus Oxide Catalysts}

Pristine (i) and two types of used VPO catalyst pellets (ii\&iii) were provided by Clariant AG.[22] The catalysts were prepared to apply the so-called organic synthesis route in which vanadium pentoxide is reacted with phosphoric acid and benzyl alcohol in isobutanol as a solvent to form the catalyst precursor vanadyl hydrogen phosphate hemihydrate $\mathrm{VOHPO}_{4} \cdot 0.5 \mathrm{H}_{2} \mathrm{O}$ ("VHP") under reflux conditions. After drying and addition of minor amounts of graphite, as an aid in the pelletizing process, the material was shaped into pellets which were finally subjected to an activation process under stepwise heating to approximately $400^{\circ} \mathrm{C}$ in a humid air/nitrogen atmosphere resulting in the catalytically active $(\mathrm{VO})_{2} \mathrm{P}_{2} \mathrm{O}_{7}$.[28] The thus produced catalyst was loaded into an industrial reactor with standard reactor tubes of a diameter of $21 \mathrm{~mm}$. The catalyst was used for four years in the production of maleic anhydride before being discharged from the reactor. Two types of used pellets were studied to showcase how the environmental heterogeneity in an industrial reactor affects the catalyst structure. One type of the used pellets (ii) was sourced from the centre of the catalyst bed, exposed to rather constant reaction conditions and temperature $\left(400^{\circ} \mathrm{C}\right)$, the other (iii) was extracted from the hot spot zone close to the feed entrance where temperatures frequently reach $460^{\circ} \mathrm{C}$ (Figure 1 a).

Physisorption measurements revealed a decrease in specific-surface-area and average pore diameter with reactor use. The surface area decreased from $20 \mathrm{~m}^{2} \mathrm{~g}^{-1}$ of the pristine catalyst (i) to $11 \mathrm{~m}^{2} \mathrm{~g}^{-1}$ (ii) and $6 \mathrm{~m}^{2} \mathrm{~g}^{-1}$ (iii) with use. The average pore diameter changed from $33 \mathrm{~nm}$ (i) to $65 \mathrm{~nm}$ (ii) and $187 \mathrm{~nm}$ (iii) (Table S1). While these changes are reflective of substantial catalyst restructuring with reactor use, accentuated in the hot spot zone, reactor productivity (mt MA h${ }^{-1}$ ) and selectivity (mol\% MA), both, dropped by only $\sim 10 \%$ over the studied period. Performance values are derived from integral measurements of the industrial reactor and as such do not allow differentiation between the two used catalysts. For the complete performance profiles, and salt-bath temperature evolution please refer to Figure S1. The feed composition, i.e., butane, water, and TMP concentrations, were held near-constant during the studied period.

Optical micrographs, Figure 1b, further revealed a change in the colour of the catalyst pellets, from dark green-blue (i) to lint green (ii) with use. The change is suggestive of vanadium atoms with a reduced oxidation state compared to the pristine catalyst. The latter possesses a nominal oxidation state of $\mathrm{V}^{4+}$, i.e. observed is a partial reduction to $\mathrm{V}^{3+}$ (see Table S1). The used catalyst pellet extracted from a reactor hot spot (iii) possesses an additional grey-blue and micron-thick surface layer of different texture. This layer is present on the outer and inner ring surface zones of the Raschig-ring-type catalyst pellets. Noteworthy, this layer is continuous on the inner ring surface but sporadic or patchy on the outer ring surface.

Powder X-ray diffraction (PXRD) of entire catalyst pellets, Figure 1c, discloses that these changes in catalyst appearance and performance are concomitant of operation-induced compositional and microstructural modifications. Compositionally, we observe a slight change in the present crystalline catalyst components. The (i) pristine VPO catalyst consists dominantly of vanadyl pyrophosphate $\left((\mathrm{VO})_{2} \mathrm{P}_{2} \mathrm{O}_{7}\right)$, with minor amounts of VOHPO $4 \cdot 4 \mathrm{H}_{2} \mathrm{O}$ and $\mathrm{V}\left(\mathrm{PO}_{3}\right)_{3}$ contributing combined well less than $10 \%$ of the crystalline material and nearly no $\mathrm{VOPO}_{4}$. The used pellets (ii\&iii) are still dominantly composed of $\left(\mathrm{VO}_{2} \mathrm{P}_{2} \mathrm{O}_{7}\right.$. The amount of the minor phases however increases and changes significantly. In the case of the used pellet (ii) we see a reduction in $\mathrm{VOHPO}_{4} \cdot 4 \mathrm{H}_{2} \mathrm{O}$ and an increase in $\mathrm{VOPO}_{4}$ and $\mathrm{V}\left(\mathrm{PO}_{3}\right)_{3}$ content. For the hot spot extracted pellet (iii) this trend appears intensified. In other words, on average we observe a minor shift in composition towards $\mathrm{V}^{5+}$ and $\mathrm{V}^{3+}$ based components $\left(\mathrm{VOPO}_{4}\right.$ and $\left.\mathrm{V}\left(\mathrm{PO}_{3}\right)_{3}\right)$ with reactor operation. A shift or transition is enhanced in the reactor hot spot zones, but 
still minor, as the catalyst pellets on average are still composed of well over $80 \%$ of vanadyl pyrophosphate after long-term reactor use. In combination, the observed and uniform change in pellet colour towards lint green with reactor use suggests the change in pellet colour to derive from a structural modification of the vanadyl pyrophosphate crystals with reactor use. Some microstructural transformation of the vanadyl pyrophosphate following reactor use is indeed evident in the diffraction patterns. Observable is a decrease in amorphous solids with use and an increase in the average coherent domain of grain size of $(\mathrm{VO})_{2} \mathrm{P}_{2} \mathrm{O}_{7}$. The latter grows from $<250$ $\mathrm{nm}$ in the pristine catalyst to on average greater than $500 \mathrm{~nm}$ for both used catalysts. Changes in grain size suggest the presence of grain growth or coarsening process with the operation.[29] A process, that is based on changes in the Bragg reflection intensity of the $\{024\}$ and $\{200\}$ reflections, also alters the morphology of the $(\mathrm{VO})_{2} \mathrm{P}_{2} \mathrm{O}_{7}$ domains. Observable is a relative intensity decrease in the $\{200\}$ reflections $(\sim 10 \%)$. As the corresponding facets have been suggested to expose most of the selective active sites, $[16,30,31]$ this change correlates well with the measured reduction in catalyst selectivity. Furthermore, visible in these pellet-averaged diffraction patterns is a slight shift of the (200) reflection towards a larger d-spacing, as well as the detection of shoulders or satellite reflections in the used catalyst around this reflection (Figure 1c). Both shift and satellite formation are more pronounced in the hot spot extracted sample. While the shift can be explained by a uniaxial elongated unit cell or macrostrain, satellite formation is yet in need of an explanation. Detailed structure refinement of these catalysts is the topic of a follow-up study having access to higher quality diffraction data.

\section{Scanning X-ray Diffraction of Vanadium Phosphorus Oxide Catalyst Pellets}

To visualize how reactor use affects the composition and crystallinity of the pellets locally, we deferred to scanning $\mathrm{X}$-ray diffraction (Figure 1d). The required thin sections, up to $20 \mu \mathrm{m}$ in thickness, extracted central-height of the pellet, were prepared using resin embedding and mechanical polishing. Sections were deposited on silicon nitride membranes. Thin sections provide a radial and cross-sectional view of one pellet quadrant (Figure 1). A perspective that allows us to investigate how proximity to the main feed stream relates to changes across the catalyst pellet width. The pixel size of the obtained diffraction maps $2 \times 2 \mu \mathrm{m}^{2}$, to improve the signal-to-noise ratio maps were binned to $4 \mathrm{x} 4 \mu \mathrm{m}^{2}$ for evaluation. Shown in Figure 1d is an example of a pixel-level diffraction pattern and a scanning diffraction map. Please refer to the Supporting Information and Figure S2 for acquisition details. Animations of the acquired diffraction maps are provided in Movie S1-S3.

\subsection{Compositional Analysis}

Figure 2 shows the projected density and compositional maps of the main catalyst components. Presented from top to bottom is the distribution of the five most abundant catalyst components, $(\mathrm{VO})_{2} \mathrm{P}_{2} \mathrm{O}_{7}$, amorphous solids, VOHPO $4 \cdot 4 \mathrm{H}_{2} \mathrm{O}, \mathrm{V}\left(\mathrm{PO}_{3}\right)_{3}$, and $\mathrm{VOPO}_{4}$, in the three catalyst bodies.

(i) The pristine VPO catalyst pellet possesses a mostly uniform density and homogenous composition. However, visible is a slight density gradient, with areas close to the inner ring surface possessing a lower density compared to areas close to the outer ring surface. Looking at the distribution of the two predominant catalyst components, $(\mathrm{VO})_{2} \mathrm{P}_{2} \mathrm{O}_{7}$ and amorphous solids, this density gradient appears to derive from a compositional zonation between these two phases. While both phases are present throughout the pristine catalyst, contributing, 
on average in this pellet $\sim 80$ and $\sim 20 \%$ respectively, amorphous solids, e.g., vanadium metaphosphate and carbon, are found enriched in the less dense areas close to the inner ring surface. Vice versa, more $(\mathrm{VO})_{2} \mathrm{P}_{2} \mathrm{O}_{7}$ is found in high-density regions located close to the outer ring surface. Furthermore, it appears that amorphous solids preferentially occupy/ are associated with the macroscopic pore space inside of the pristine catalyst (black arrow, Figure 2i). The latter may be a result of the above-described activation process. During activation, the VHP precursor is dehydrated to the catalytically active $(\mathrm{VO})_{2} \mathrm{P}_{2} \mathrm{O}_{7}$. As this process is carried out in steam containing atmosphere where diffusion into the pore structure of the catalyst could be a limiting constraint, we expect the material building up in the macroscopic pore space to be the subject of multiple dehydration and re-hydration cycles during catalyst activation. In other words, a fraction of the catalyst internal water originating from the transformation of VHP to $(\mathrm{VO})_{2} \mathrm{P}_{2} \mathrm{O}_{7}$ maybe temporarily re-adsorb on the catalyst surface before being entirely removed from the pellet, a process that could facilitate nanocrystalline or amorphous solids formation. The minor components, $\mathrm{VOHPO}_{4} \cdot 4 \mathrm{H}_{2} \mathrm{O}$ and $\mathrm{V}\left(\mathrm{PO}_{3}\right)_{3}$, are found homogeneously distributed throughout the catalyst at the achieved spatial resolution. The nominally $\mathrm{V}^{5+}$ representing $\mathrm{VOPO}_{4}$ is found preferentially on the pellet exterior surfaces.

(ii) With utilization in the reactor, both the density and the compositional distribution of present materials changes. For the used VPO catalyst pellet, extracted from the centre of the catalyst bed (Figure 2ii), observable is a homogenous density in the centre of the pellet. The density increases in the outermost microns, on both the inner and outer ring surface; potentially a result of thermal stress-induced grain growth and or pore closure/ collapse. [7, $32,33]$ This change in density correlates with an apparent increase in $(\mathrm{VO})_{2} \mathrm{P}_{2} \mathrm{O}_{7}$ content on both exterior surfaces. Interestingly, and unlike the pristine catalyst pellet, the outermost microns are nearly completely composed of $(\mathrm{VO})_{2} \mathrm{P}_{2} \mathrm{O}_{7}$, and are followed by spatially-extended troughs of reduced $(\mathrm{VO})_{2} \mathrm{P}_{2} \mathrm{O}_{7}$ presence $(<80 \%)$ close to the pellet exterior before reaching a compositional crest of $(\mathrm{VO})_{2} \mathrm{P}_{2} \mathrm{O}_{7}$ in the interior centre of the imaged quadrant. Dispersed in the pellet centre are micron-sized islands entirely composed of $(\mathrm{VO})_{2} \mathrm{P}_{2} \mathrm{O}_{7}$ being absent in the pristine catalyst. This relative increase in $(\mathrm{VO})_{2} \mathrm{P}_{2} \mathrm{O}_{7}$ with reactor use is at the expense of amorphous solids and VOHPO $4 \cdot 4 \mathrm{H}_{2} \mathrm{O}$. Notably, their distribution is a negative image of the $(\mathrm{VO})_{2} \mathrm{P}_{2} \mathrm{O}_{7}$ distribution. Distribution profiles are suggestive of phase transformation processes that depend on the distance to the exterior pellet surface. Distribution profiles of $\mathrm{V}\left(\mathrm{PO}_{3}\right)_{3}$ and $\mathrm{VOPO}_{4}$ echo this suggestion. Still contributing on average less than $5 \%$ of the material visible is a significant increase in their presence compared to the pristine catalyst. While the $\mathrm{V}\left(\mathrm{PO}_{3}\right)_{3}$ distribution mirrors the distribution of amorphous solids and $\mathrm{VOHPO}_{4} \cdot 4 \mathrm{H}_{2} \mathrm{O}, \mathrm{VOPO}_{4}$ deviates from this pattern. Instead, we observe the formation of individual islands with selected pixels reaching a compositional contribution of $30 \%$, located overall closer to the outer ring surface. The existence of two zonation patterns for such chemically distinct components as $\mathrm{V}\left(\mathrm{PO}_{3}\right)_{3}$ and $\mathrm{VOPO}_{4}$, suggests the existence of two transformation processes. Colocalization implies $\mathrm{VOPO}_{4}$ to form at the expenditure of $(\mathrm{VO})_{2} \mathrm{P}_{2} \mathrm{O}_{7}$, i.e., through an oxidation process.[34, 35] While this transformation is benefitting from an increased reaction temperature, the distribution throughout the pellet in the form of micron-sized islands suggests this process not to be entirely dependent on the presence of either butane or oxygen at the observable length scale. $\mathrm{V}\left(\mathrm{PO}_{3}\right)_{3}$ on the other hand appears to form at the expense of amorphous solids or $\mathrm{VOHPO}_{4} \cdot 4 \mathrm{H}_{2} \mathrm{O}$, a transformation process given the localisation towards the reaction medium fostered by the increased presence of $\mathrm{H}_{2} \mathrm{O}$ in this region. $[33,36]$

(iii) Distribution profiles of the hot spot extracted VPO catalyst pellet (Figure 2iii), support these suggestions. The density distribution reveals the presence of a comparatively low-density interior flanked by two high-density rings facing towards the exterior surfaces. Furthermore, and selectively found on the inner ring 
surface is another low-density layer. The absence of such a layer and the comparatively patchy high-density layer on the outer ring surface coincides with a slightly smaller ring diameter of this pellet compared to the pristine and the used pellet extracted from a colder reactor zone (i\&ii). Compositionally, the density profile can be broken down as follows. $(\mathrm{VO})_{2} \mathrm{P}_{2} \mathrm{O}_{7}$ still represents the most abundant component, however observable is a reduction to $\sim 50-70 \%$ in the high-density rings and in selected areas close to both exterior surfaces to less than $5 \%$. The fraction of amorphous solids in this pellet is even less compared to the used catalyst outside of the hot spot $(\sim 10 \%)$. The central low-density region is poorer in amorphous solids, compared to the surrounding high-density rings. The relative reduction in both of these components is at the hands of $\mathrm{V}\left(\mathrm{PO}_{3}\right)_{3}$ and $\mathrm{VOPO}$, with $\mathrm{V}\left(\mathrm{PO}_{3}\right)_{3}$ abundant throughout the pellet and dominantly populating both exterior-facing surfaces. $\mathrm{VOPO}_{4}$ again reveals a differing distribution. While also present on the exterior surfaces, the distribution follows that of $(\mathrm{VO})_{2} \mathrm{P}_{2} \mathrm{O}_{7}$, i.e., more abundant in the central low-density interior.

\subsection{Microstructural Analysis}

In face of the ubiquity of vanadyl pyrophosphate and PXRD detected changes in Bragg reflection intensity, microstructural analysis focused on the (200) and (024) reflection of vanadyl pyrophosphate.

Figure 3a provides maps that display the local intensity ratio between (200) and (024) reflections of vanadyl pyrophosphate of the three catalyst pellets (i-iii). According to these maps, we observe a morphological transition of coherent scattering domains towards a reduced expression of the catalytically active $\{200\}$ facets following reactor use. This change is less obvious in the case of the pellet extracted from the catalyst bed centre (ii), more visible here is a spatial rearrangement, i.e., we observe a relatively higher intensity of the (200) reflection in areas closer to the outer ring surface. Such a zonation is absent in the pristine catalyst, and in line with the compositional changes of the used catalyst and a further indicator of spatially uneven thermal stress across the pellet.[37] In the case of the pellet extracted from the hot spot (iii), we observe throughout the pellet comparatively reduced (200) intensities.

Figure $3 \mathrm{~b}$ displays local micro strain evaluations extracted from either the (200) or the (024) reflection of vanadyl pyrophosphate.[38, 39] (i) Visible in the micro strain maps of the pristine catalyst is a near homogenous strain profile (Figure 3bi). Noteworthy, micro strain evaluations from either reflection are very similar in magnitude and distribution. A minor difference being an increase in micro strain from the inner ring towards the outer ring surface, selectively visible in the (024) based evaluations and correlated with the amorphous solids' distribution (Figure 2i). (ii) Following reactor use, we observe an increase in micro strain in both catalyst pellets (ii \& iii). Interestingly, this increase is significantly more pronounced in the (200) based evaluations in both pellets, potentially speaking to the more active utilization of corresponding surfaces. The used pellet extracted from the centre of the reactor (Figure $3 \mathrm{~b}$ ii) reveals a strain profile mirroring the distribution of the two most abundant catalyst components in the pellet. Observed are enhanced strain levels in the centre of the pellet occupied dominantly by vanadyl pyrophosphate, with regions closer to the outer ring surface known to be rich in amorphous solids experiencing less strain. (iii) For the hot spot extracted pellet (Figure 3b iii), we observe a similar pattern in the (200) based evaluations, with regions richer in amorphous solids, such as the two-high density rings, to be less strained. This is compared to the centre of the pellet, possessing more vanadyl pyrophosphate, being more strained. The enhanced strain level in the outermost microns/ pixel on both the inner and outer ring surface, visible in all three samples, can be attributed to sample preparation introduced artefacts. 


\section{Discussion}

Taken together, these observations advocate for the presence of the well-known heat and mass transport limitations within the catalyst pellets under reactor operation conditions, resulting in increased thermal stress and catalytic load on the inner and outer ring regions of the pellet.[27]

The pellet-average loss of amorphous solids and increase in porosity, i.e., the catalyst fine structure,[7] with reactor use can in part be explained by wear and grain growth processes. The presence of diffusion limitations, for example, represented by a gradient in the water concentration across the pellet width, i.e., a higher concentration at the exterior compared to the interior of the pellet, could provide an explanation for the developing compositional zonation with reactor use. This is based on the knowledge that water encourages the transformation and back reaction of $(\mathrm{VO})_{2} \mathrm{P}_{2} \mathrm{O}_{7}$ to $\mathrm{VOHPO}_{4} \cdot 4 \mathrm{H}_{2} \mathrm{O}$ and amorphous solids.[22, 23] A gradient in water concentration within the pellet would, hence, foster the formation of amorphous solids close to the exterior and explain the relative increase in $(\mathrm{VO})_{2} \mathrm{P}_{2} \mathrm{O}_{7}$ in the more interior regions of the pellet. Furthermore, limited transport of water to the catalyst interior and poor heat removal from the catalyst would aid the generation of $\mathrm{V}^{5+}$ species $\left(\mathrm{VOPO}_{4}\right)$ in the pellet interior. The detection of isolated $\mathrm{VOPO}_{4}$ clusters in the used and, especially, in the hotspot extracted pellet interior moreover implies the presence of particularly isolated domains, and as such local overheating within the pellet $\left(\mathrm{VOPO}_{4}\right.$ formation is favoured at higher temperatures.).[34] A similar process might take place for the formation of $\mathrm{V}\left(\mathrm{PO}_{3}\right)_{3}$ in regions closer to the pellet's exterior, i.e. governed by the increased mobility of P-containing species.

The suggested differences in environmental conditions and mentioned transformations across the pellet width may also explain the reduced expression/ changing relative intensity distribution of the $\{200\}$ facets of $(\mathrm{VO})_{2} \mathrm{P}_{2} \mathrm{O}_{7}$ with reactor use. Here, we consider an environment-dependent adaptation of different $(\mathrm{VO})_{2} \mathrm{P}_{2} \mathrm{O}_{7}$ morphologies (Figure 3a) as a result of ongoing grain coarsening across the pellet and the preferred dissolution/ amorphisation of locally present $(\mathrm{VO})_{2} \mathrm{P}_{2} \mathrm{O}_{7}$ close to the exterior, both altering the relative reflection intensity.

The pellet-average increase in micro strain with reactor use, we attribute to the catalytic load/use of the material (Figure 3bii) as well as the grain coarsening of the material. The marked strain distribution in the hot-spot extracted pellet (Figure 3biii), i.e., the relatively reduced strain level of $(\mathrm{VO})_{2} \mathrm{P}_{2} \mathrm{O}_{7}$ in the high-density layers (Figure 2iii), is possibly the result of (a) the water-induced transformation of a fraction of locally present $(\mathrm{VO})_{2} \mathrm{P}_{2} \mathrm{O}_{7}$ and or (b) the result of a fractional amorphization of the present $(\mathrm{VO})_{2} \mathrm{P}_{2} \mathrm{O}_{7}$ to release the stress-induced strain in this region of the pellet.

Lastly, the newly deposited low-density layer on the inner ring surface of the hot-spot extracted sample (Figure 3iii) in combination with its patchy outer ring exterior (Figurelb iii grey-blue outer surface), implies environmental conditions in the hot-spot to locally weaken the structural integrity of the pellet. We currently foresee two possible origins for the deposited inner and the patchy outer layer. (1) Use wear of the outer ring surface and the pellet interior fine structure followed by a re-deposition of material on the inner ring surface. The latter being less subjective to wear. (2) Used catalyst discharge from an industrial reactor. During discharging, i.e. prior to analysis, the catalyst pellets experience a physical fall out of the production reactors by up to 6 meters. Fall through the tube and the following impact on the collecting bucket may result in an abrasion on the outer ring surface of the pellet and fine particle formation. The latter, as ultrafine dust, might possibly re-deposit on the inner ring surface. 
To consider how the detected changes may affect the catalyst's performance, we follow the consensus that $(\mathrm{VO})_{2} \mathrm{P}_{2} \mathrm{O}_{7}$ is the active material and that the catalytic activity scales with its crystallinity. This is while acknowledging the nature of active sites (suggested have been a vast number of surface modifications and secondary colocalized oxide species), the role of water and TMP dosing during the reaction are still widely debated.[5, 10, 33, 36] A fraction of these debates arise from: The study of model systems that are not representative of the industrial in-use catalyst, our inability to mirror industrial conditions, or the examination of catalysts that are not equilibrated. The provided examination of catalyst pellets extracted from an industrial reactor of known operation history reiterates this notion. Performance profiles (Figure S1), imply that the catalysts undergo an evolution for years before reaching a steady composition and structure. At this stage, i.e., after four years of operation, the catalysts still display a remarkable performance compared to the pristine catalyst. Remarkably, as despite a loss in a minimum of $50 \%$ of surface area and an increase in pore diameter, we only observe a $10 \%$ drop in productivity and because of the needed salt bath temperature increase also in selectivity. On a surface-areaspecific basis, the used catalyst performs better than the pristine catalyst, assuming an unchanging active site density.

Bulk characterisation and scanning XRD mapping propose this level of productivity is retained through: (1) A relative increase in vanadyl pyrophosphate crystallinity, domain size, and amount with reactor use (ii), i.e. a spatially higher density of active sites compared to the pristine catalyst; (2) An increase in porosity and average pore diameter (Table S1), possibly lessening in later stages of reactor operation initial mass transport limitations. Combined these factors might offset the loss of, potentially, active surface area with continued reactor use and the spatially unequal catalytic utilization of the pellet. [33-36] Ignoring the nature of the involved active site(s) for a moment, and focusing solely on the increasing understanding that the (200) planes of vanadyl pyrophosphate are the most selective.[5, 10,33,36] The observed decrease in selectivity can be explained by an overall decreasing expression of $\{200\}$ facets.

Lastly, on the importance of secondary vanadium pyrophosphate oxides for the performance VPO catalysts. We are doubtful that the sparse distribution of larger deposits of $\mathrm{V}\left(\mathrm{PO}_{3}\right)_{3}$ and $\mathrm{VOPO}_{4}$ detectable in this study exert a substantial effect on the catalytic performance. The limited spatial resolution and sensitivity of these measurements make it however impossible to provide any comment on the presence and importance of nanocrystalline domains of these secondary oxides on top vanadyl pyrophosphate crystals towards VPO activity and the reaction mechanism.[10,36]

\section{Conclusion}

In summary, scanning X-ray diffraction allowed us to visualize how utilization and location in an industrial reactor impact the structure, composition, and structural integrity of state-of-the art VPO catalyst pellets.[10] These investigations suggest a spatially non-uniform and un-optimized utilization of the catalyst pellets in line with the well-known low pore utilization especially in the hotspot zone, as a result of heat and mass transport limitations. These limitations promote spatial heterogeneity within the pellet in the form of a more heavily altered exterior, including changes in apparent porosity, an increase in amorphous solids as well as the formation of performance impacting oxides. These changes are more pronounced in hot spot zones of the industrial reactor.

These results reiterate the importance of characterizing heterogeneous catalysts at all length scales to understand their performance and to optimize their design for the industrial setting. 
[1] M. Ruitenbeek, R.A. Overbeek, D.C. Koningsberger, J.W. Geus, The Selective Oxidation of NButane to Maleic Anhydride; Development of Silica-and Titania Supported V-P-O Catalysts, in: E.G. Derouane, J. Haber, F. Lemos, F.R. Ribeiro, M. Guisnet (Eds.) Catalytic Activation and Functionalisation of Light Alkanes: Advances and Challenges, Springer Netherlands, Dordrecht, 1998, pp. 423-427.

[2] Maleic Anhydride, Maleic Acid, and Fumaric Acid, Kirk-Othmer Encyclopedia of Chemical Technology.

[3] G.J. Hutchings, Heterogeneous catalysts-discovery and design, Journal of Materials Chemistry, 19 (2009) 1222-1235.

[4] B.K. Hodnett, Vanadium-Phosphorus Oxide Catalysts for the Selective Oxidation of C4 Hydrocarbons to Maleic Anhydride, Catalysis Reviews, 27 (1985) 373-424.

[5] M. Ruitenbeek, Characterisation of Vanadium-Based Oxidation Catalysts, Utrecht University, Utrecht, 1999.

[6] N.F. Dummer, J.K. Bartley, G.J. Hutchings, Chapter 4 - Vanadium Phosphate Materials as Selective Oxidation Catalysts, in: B.C. Gates, H. Knözinger (Eds.) Advances in Catalysis, Academic Press2011, pp. 189-247.

[7] Z. Gao, M. Odstrcil, S. Böcklein, D. Palagin, M. Holler, D. Ferreira Sanchez, F. Krumeich, A. Menzel, M. Stampanoni, G. Mestl, J.A. van Bokhoven, M. Guizar-Sicairos, J. Ihli, Sparse X-ray Transmission Spectro-Tomography Facilitates 3D Chemical Speciation of Heterogeneous Catalysts on the Nanoscale, Submitted.

[8] G. Centi, F. Trifiro, J.R. Ebner, V.M. Franchetti, Mechanistic aspects of maleic anhydride synthesis from C4 hydrocarbons over phosphorus vanadium oxide, Chemical Reviews, 88 (1988) 55-80.

[9] Z.-Y. Xue, G.L. Schrader, In Situ Laser Raman Spectroscopy Studies of VPO Catalyst Transformations, The Journal of Physical Chemistry B, 103 (1999) 9459-9467.

[10] D. Lesser, Dynamic Behavior of Industrial Fixed Bed Reactors for the Manufacture of Maleic Anhydride, Department of Mathematikl/Inofrmatik und Maschinenbau, Technical University Clausthal, 2016, pp. 1574.

[11] P.L. Gai, K. Kourtakis, Solid-State Defect Mechanism in Vanadyl Pyrophosphate Catalysts: Implications for Selective Oxidation, Science, 267 (1995) 661-663.

[12] G.J. Hutchings, A. Desmartin-Chomel, R. Olier, J.-C. Volta, Role of the product in the transformation of a catalyst to its active state, Nature, 368 (1994) 41-45.

[13] G. Bergeret, M. David, J.P. Broyer, J.C. Volta, G. Hecquet, A contribution to the knowledge of the active sites of VPO catalysts for butane oxidation to maleic anhydride, Catalysis Today, 1 (1987) 3747.

[14] H. Morishige, J. Tamaki, N. Miura, N. Yamazoe, Amorphous V\&ndash;P Mixed Oxide with P/V = 2.0 as Active Phase for Butane Oxidation, Chemistry Letters, 19 (1990) 1513-1516.

[15] A. Brückner, A. Martin, B. Kubias, B. Lücke, Structure of vanadium sites in VPO catalysts and their influence on the catalytic performance in selective $\mathrm{O}$ - and $\mathrm{N}$-insertion reactions, Journal of the Chemical Society, Faraday Transactions, 94 (1998) 2221-2225.

[16] G.J. Hutchings, Vanadium phosphate: a new look at the active components of catalysts for the oxidation of butane to maleic anhydride, Journal of Materials Chemistry, 14 (2004) 3385-3395.

[17] F. Benzi, G. Giuli, S. Della Longa, E. Paris, Vanadium K-edge XANES in vanadium-bearing model compounds: a full multiple scattering study, Journal of Synchrotron Radiation, 23 (2016) 947-952.

[18] J. Wong, F.W. Lytle, R.P. Messmer, D.H. Maylotte, K-edge absorption spectra of selected vanadium compounds, Physical Review B, 30 (1984) 5596-5610.

[19] D.J. Thompson, M.O. Fanning, B.K. Hodnett, Modelling the active sites in vanadyl pyrophosphate, Journal of Molecular Catalysis A: Chemical, 198 (2003) 125-137. 
[20] M.-J. Cheng, W.A. Goddard, R. Fu, The Reduction-Coupled Oxo Activation (ROA) Mechanism Responsible for the Catalytic Selective Activation and Functionalization of $\mathrm{n}$-Butane to Maleic Anhydride by Vanadium Phosphate Oxide, Topics in Catalysis, 57 (2014) 1171-1187.

[21] M. Ruitenbeek, A. Barbon, E.E.v. Faassen, J.W. Geus, Evidence for a new type of vanadyl pairs in $(\mathrm{VO})_{2} \mathrm{P}_{2} \mathrm{O}_{7}$ : an ESR and magnetisation study, Catalysis Letters, 54 (1998) 101-104.

[22] A. Bortinger, G. Mazzoni, T. Monti, Phosphorus/vanadium catalyst preparation, in: P.S.S.D.C. Inc (Ed.), 2003.

[23] S. Böcklein, G. Mestl, S.V. Auras, J. Wintterlin, On the Correlation of Structure and Catalytic Performance of VPO Catalysts, Topics in Catalysis, 60 (2017) 1682-1697.

[24] N.F. Dummer, W. Weng, C. Kiely, A.F. Carley, J.K. Bartley, C.J. Kiely, G.J. Hutchings, Structural evolution and catalytic performance of DuPont $\mathrm{V}-\mathrm{P}-\mathrm{O} / \mathrm{SiO} 2$ materials designed for fluidized bed applications, Applied Catalysis A: General, 376 (2010) 47-55.

[25] J. Ihli, L. Bloch, F. Krumeich, K. Wakonig, M. Holler, M. Guizar-Sicairos, T. Weber, J.C. da Silva, J.A. van Bokhoven, Hierarchical Structure of NiMo Hydrodesulfurization Catalysts Determined by Ptychographic X-Ray Computed Tomography, Angewandte Chemie International Edition, n/a.

[26] E.H.R. Tsai, J. Billaud, D.F. Sanchez, J. Ihli, M. Odstrčil, M. Holler, D. Grolimund, C. Villevieille, M. Guizar-Sicairos, Correlated X-Ray 3D Ptychography and Diffraction Microscopy Visualize Links between Morphology and Crystal Structure of Lithium-Rich Cathode Materials, iScience, 11 (2019) 356-365.

[27] Y. Dong, M. Geske, O. Korup, N. Ellenfeld, F. Rosowski, C. Dobner, R. Horn, What happens in a catalytic fixed-bed reactor for $n$-butane oxidation to maleic anhydride? Insights from spatial profile measurements and particle resolved CFD simulations, Chemical Engineering Journal, 350 (2018) 799811.

[28] A. Bortinger, Phosphorous/Vanadium Catalyst Preparation, United States of America, 2003.

[29] P.W. Voorhees, The theory of Ostwald ripening, Journal of Statistical Physics, 38 (1985) 231-252.

[30] M. Misono, Selective Oxidation of Butanes. Toward Green/Sustainable Chemistry, Topics in Catalysis, 21 (2002) 89-96.

[31] W.C. Shung, Bi-Metallic Promoted Vanadyl Pyrophosphate Catalyst for Partial Oxidation of Light Paraffin to Maleic Anhydride, Department of Chemcial Engineering University Tunku Abdul Rahman, 2017.

[32] J. Ihli, A. Diaz, Y. Shu, M. Guizar-Sicairos, M. Holler, K. Wakonig, M. Odstrcil, T. Li, F. Krumeich, E. Müller, W.-C. Cheng, J. Anton van Bokhoven, A. Menzel, Resonant Ptychographic Tomography Facilitates Three-Dimensional Quantitative Colocalization of Catalyst Components and Chemical Elements, The Journal of Physical Chemistry C, 122 (2018) 22920-22929.

[33] M.A. Carreon, V.V. Guliants, Chapter 6 Selective Oxidation of n-Butane over VanadiumPhosphorous Oxide, Nanostructured Catalysts: Selective Oxidations, The Royal Society of Chemistry2011, pp. 141-168.

[34] G. Centi, Vanadyl Pyrophosphate - A Critical Overview, Catalysis Today, 16 (1993) 5-26.

[35] G. Koyano, T. Okuhara, M. Misono, Structural Changes of Surface Layer of Vanadyl

Pyrophosphate Catalysts by Oxidation-Reduction and Their Relationships with Selective Oxidation of n-Butane, Journal of the American Chemical Society, 120 (1998) 767-774.

[36] E. Bordes, Crystallochemistry of VPO phases and application to catalysis, Catalysis Today, 1 (1987) 499-526.

[37] P. Lechner, S. Eckbauer, R. Hartmann, S. Krisch, D. Hauff, R. Richter, H. Soltau, L. Strüder, C. Fiorini, E. Gatti, A. Longoni, M. Sampietro, Silicon drift detectors for high resolution room temperature X-ray spectroscopy, Nuclear Instruments and Methods in Physics Research Section A: Accelerators, Spectrometers, Detectors and Associated Equipment, 377 (1996) 346-351.

[38] I. Polishchuk, A.A. Bracha, L. Bloch, D. Levy, S. Kozachkevich, Y. Etinger-Geller, Y. Kauffmann, M. Burghammer, C. Giacobbe, J. Villanova, G. Hendler, C.-Y. Sun, A.J. Giuffre, M.A. Marcus, L. Kundanati, P. Zaslansky, N.M. Pugno, P.U.P.A. Gilbert, A. Katsman, B. Pokroy, Coherently aligned nanoparticles within a biogenic single crystal: A biological prestressing strategy, Science, 358 (2017) 1294-1298. 
[39] B. Pokroy, A. Fitch, E. Zolotoyabko, The Microstructure of Biogenic Calcite: A View by HighResolution Synchrotron Powder Diffraction, Advanced Materials, 18 (2006) 2363-2368.

[40] N. Ballarini, F. Cavani, C. Cortelli, S. Ligi, F. Pierelli, F. Trifirò, C. Fumagalli, G. Mazzoni, T. Monti, VPO catalyst for $\mathrm{n}$-butane oxidation to maleic anhydride: A goal achieved, or a still open challenge?, Topics in Catalysis, 38 (2006) 147-156.

[41] V.A. Zazhigalov, Effect of Bismuth Additives on the Properties of Vanadium-Phosphorus Oxide Catalyst in the Partial Oxidation of n-Pentane, Kinetics and Catalysis, 43 (2002) 514-521.

[42] R.J. Davies, M. Burghammer, C. Riekel, An Overview of the ESRF's ID13 Microfocus Beamline, Synchrotron Radiation in Natural Science, 5 (2006) 96-99.

[43] I. Johnson, A. Bergamaschi, H. Billich, S. Cartier, R. Dinapoli, D. Greiffenberg, M. Guizar-Sicairos, B. Henrich, J. Jungmann, D. Mezza, A. Mozzanica, B. Schmitt, X. Shi, G. Tinti, Eiger: a single-photon counting x-ray detector, Journal of Instrumentation, 9 (2014) C05032.

[44] J. Kieffer, D. Karkoulis, PyFAI, a versatile library for azimuthal regrouping, Journal of Physics: Conference Series, 425 (2013) 202012.

[45] M. van Heel, M. Schatz, Fourier shell correlation threshold criteria, Journal of Structural Biology, 151 (2005) 250-262.

[46] J. Schindelin, I. Arganda-Carreras, E. Frise, V. Kaynig, M. Longair, T. Pietzsch, S. Preibisch, C. Rueden, S. Saalfeld, B. Schmid, J.-Y. Tinevez, D.J. White, V. Hartenstein, K. Eliceiri, P. Tomancak, A. Cardona, Fiji: an open-source platform for biological-image analysis, Nature Methods, 9 (2012) 676682. 
Acknowledgements: L.B. was supported by an ESRF - ETH collaboration contract (CL0249). J.I. is supported by the Swiss National Science Foundation (PZ00P2_179886). Scanning X-ray diffraction experiments were performed at beamline ID 13 of the European Synchrotron Radiation Facility in Grenoble, France. Frank Krumeich acquired the electron micrographs using the facilities of the Scientific Centre for Optical and Electron Microscopy (ScopeM). Andreas Jallas, Inst. für Geochemie und Petrologie, ETHzurich helped to prepare the thin sections. Clariant AG is acknowledged for the provision of samples and material characterization expertise.

Contributions: S.B., G.M., J.C.d.S. and JAVB. conceived the study. L.B. and M.B. acquired scanning X-ray diffraction data. P.R., L.B., and J.I. analysed data. F.K. acquired electron micrographs. A.J. and L.B. prepared thin sections. S.B. and G.M. provided samples and performed bulk characterisation experiments. J.I. and S.B. wrote the manuscript. All authors contributed to the discussion, read and approved the manuscript.

Declaration of Interests: The authors declare that they have no known competing financial interests or personal relationships that could have appeared to influence the work reported in this paper.

\section{Data Availability:}

The data that support the findings of this study are available from the corresponding author upon request. 


\section{TOC Entry}

\section{Structural and Compositional Heterogeneity in Selective Oxidation Catalyst Pellets; Expressions of Industrial Use}

Scanning X-ray diffraction is used to visualize compositional and structural changes in selective oxidation catalyst bodies as a function of location and utilization in an industrial reactor.

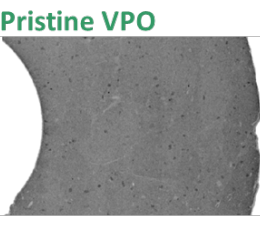

Density

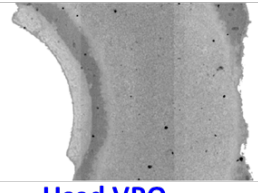

Used VPO

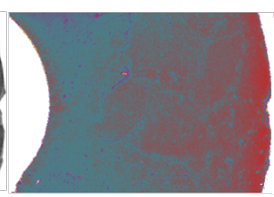

$(\mathrm{VO})_{2} \mathrm{P}_{2} \mathrm{O}_{7}$

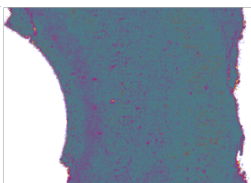

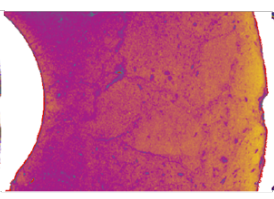

Amorphous Solids

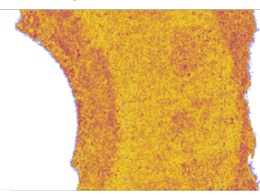

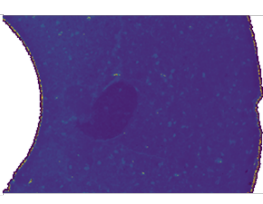

Strain

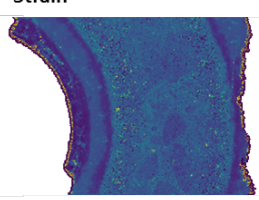

\section{Highlights}

- Performance Profile of an Industrial Vanadium Phosphorus Oxide (VPO) Reactor.

- Compositional and Structural Changes of a VPO Catalyst Under Industrial Conditions.

- Visualization of Catalyst Body Heterogeneities as a function of Reactor Location.

- Loss of Amorphous Solids and Porosity Increases Industrial VPO Catalyst Performance. 


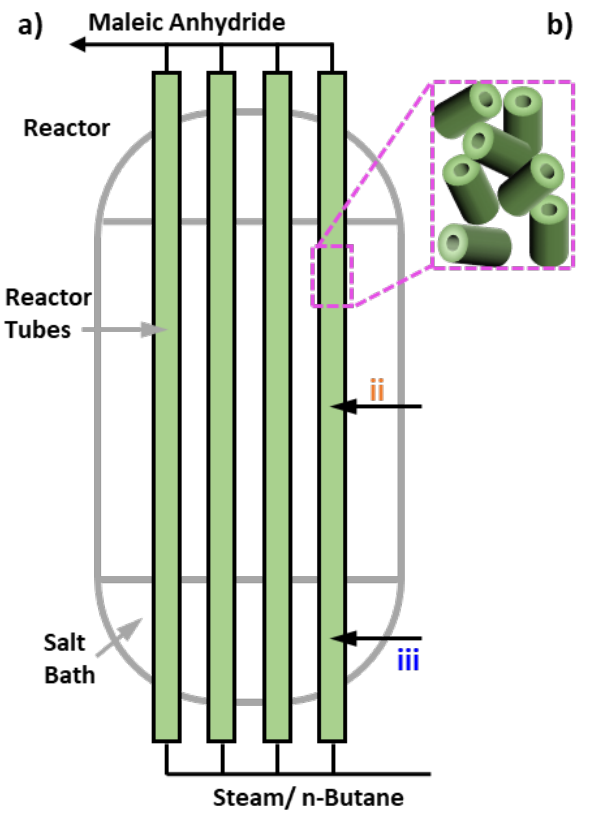

b)
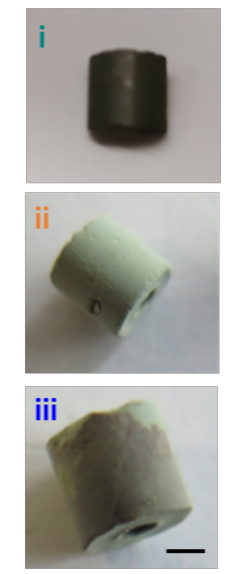

Dissect \& c)
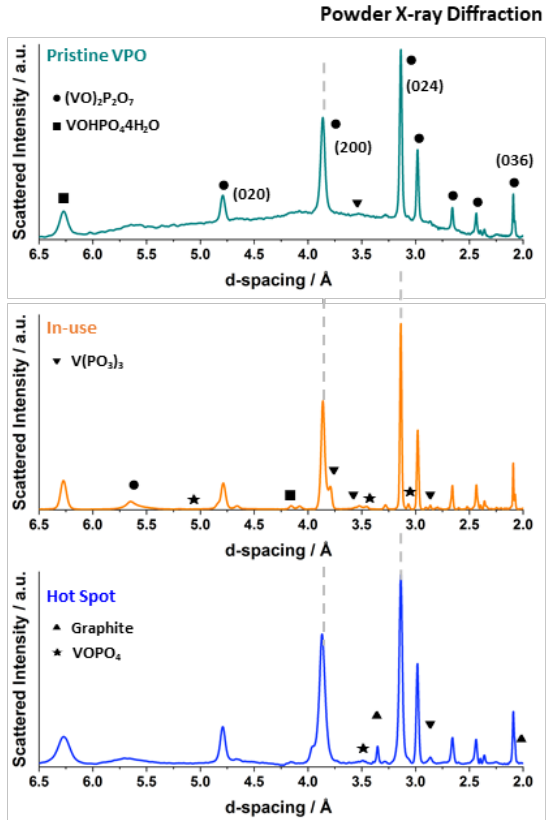

d)

Scanning X-ray Diffraction Microscopy

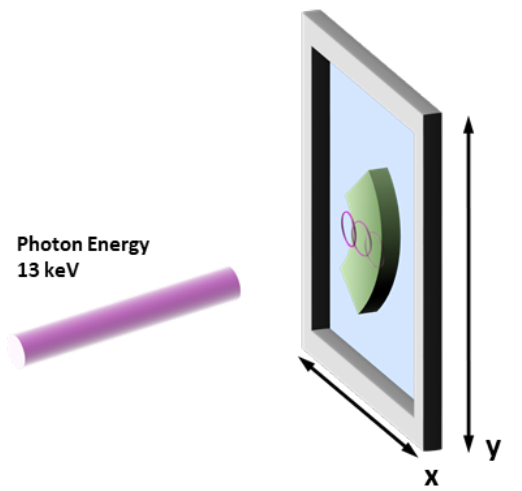

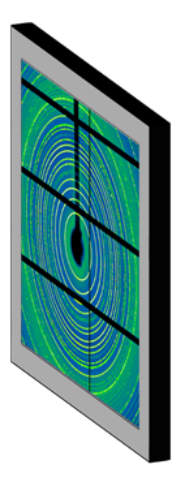

Azimuthal Integration

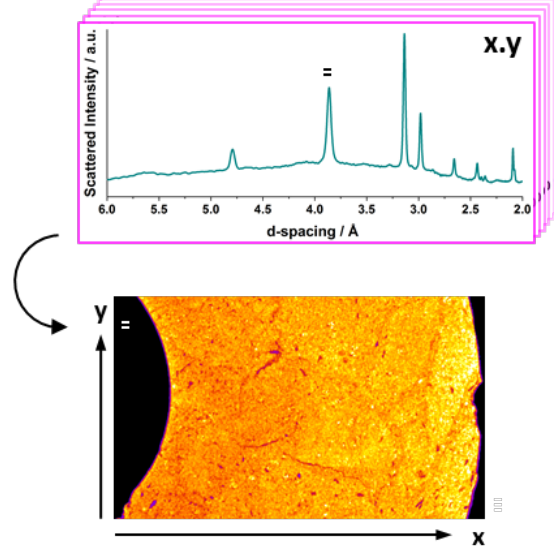

Figure 1: Powder and Scanning X-ray Diffraction of Industrial Vanadium Phosphorus Oxide (VPO) Catalyst Pellets. (a) Schematic representation of a fixed-bed reactor and VPO catalyst bed utilized in the selective oxidation of n-butane to maleic acid. (b) Optical micrographs of the Raschig ring-type VPO catalyst pellets. Shown are a pristine (i), an in-use pellet (ii), and a pellet extracted from a reactor hot spot zone (iii). The general extraction locations are indicated in (a). Scale bar is $1.5 \mathrm{~mm}$. (c) Catalyst pellet averaged PXRD patterns. Selected Bragg reflections of prominent crystalline catalyst components are highlighted. (d) Scanning X-ray diffraction acquisition scheme. A series of two-dimensional diffraction patterns were acquired by raster-scanning $(x-y)$ a thinned catalyst pellet quadrant. Following azimuthal integration, these patterns can be assembled into scanning X-ray diffraction maps, for example, stressing the distribution of selected crystalline phases. This is here demonstrated for a pristine catalyst pellet, showing the $(\mathrm{VO})_{2} \mathrm{P}_{2} \mathrm{O}_{7}$ distribution using a singular selected reflection. 
(i) Pristine VPO

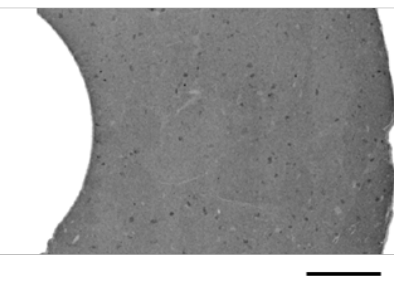

(VO) ${ }_{2} \mathrm{P}_{2} \mathrm{O}_{7}$

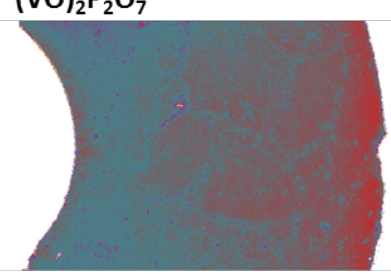

Amorphous Solids

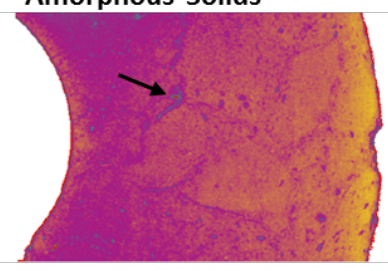

$\mathrm{VOHPO}_{4} \cdot 4 \mathrm{H}_{2} \mathrm{O}$

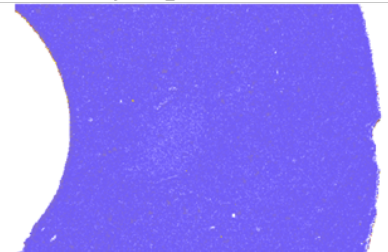

$\mathrm{V}\left(\mathrm{PO}_{3}\right)_{3}$ (ii) Used VPO

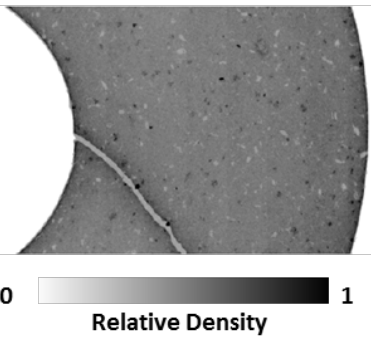

Relative Density
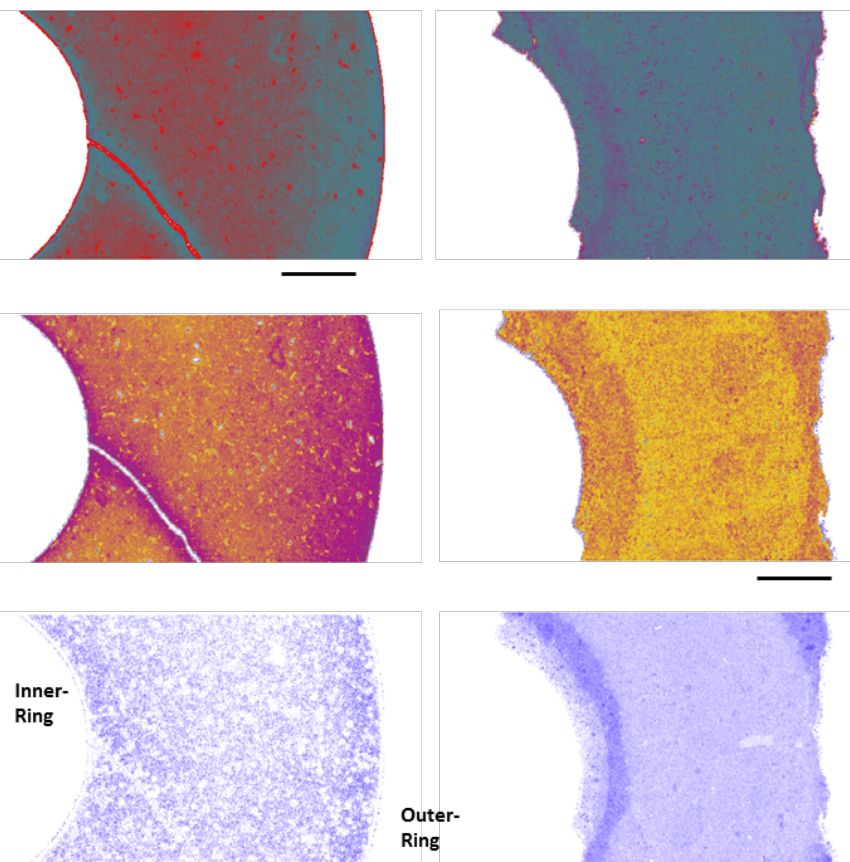

Ring

(iii) Used Hot Spot

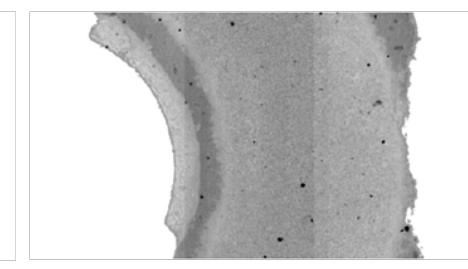

Mass Fraction
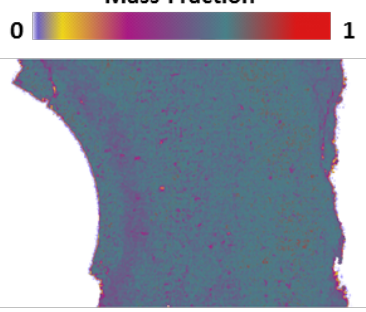

1
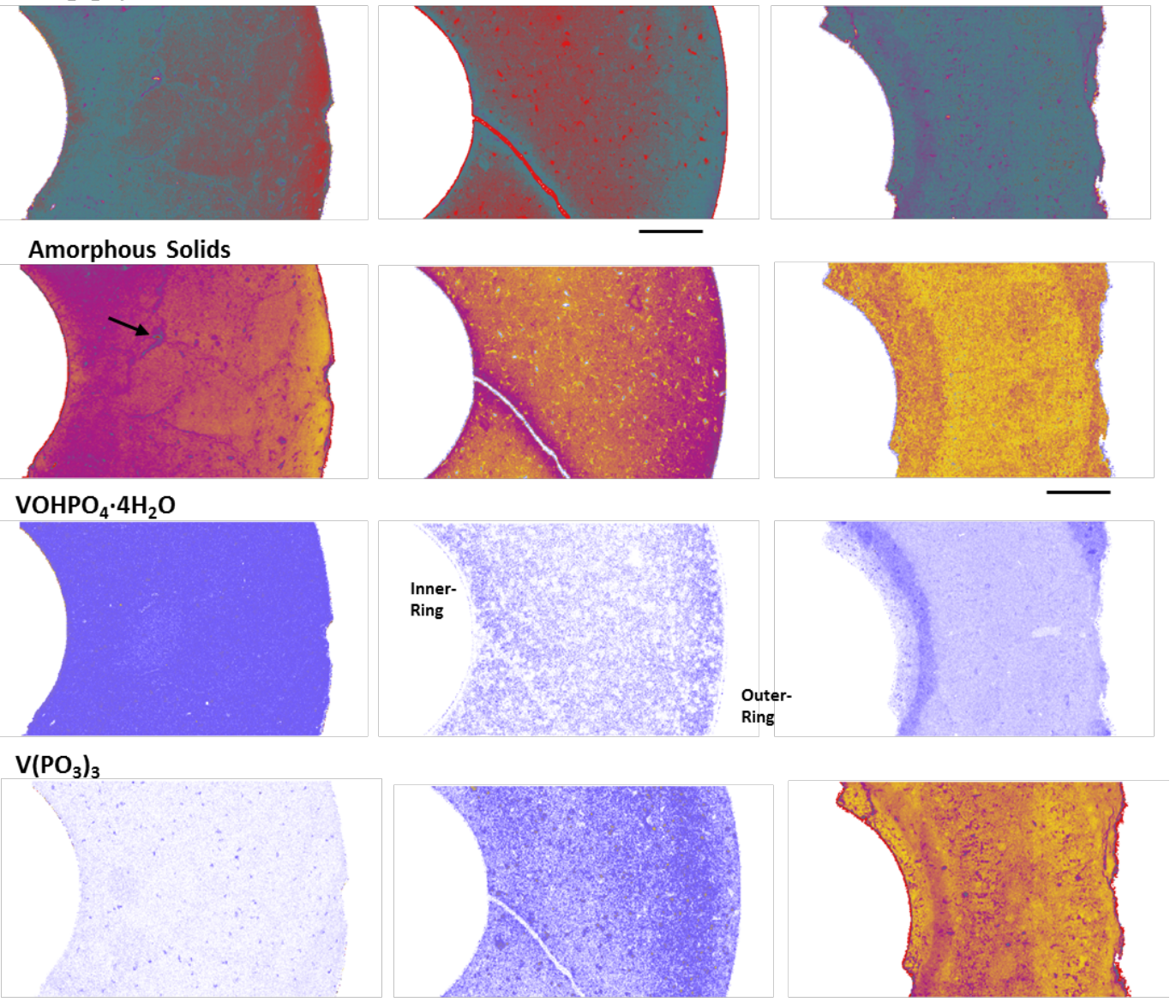

VOPO $_{4}$
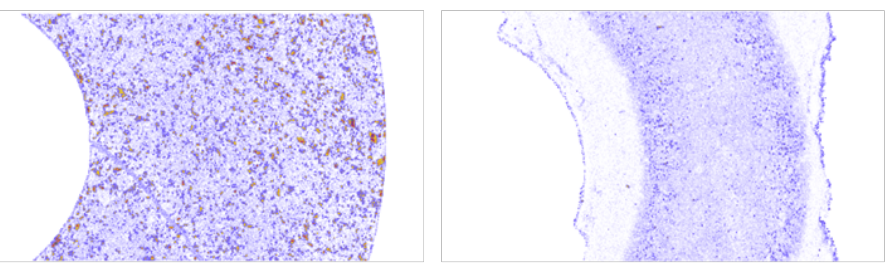

Figure 2: Compositional Mapping of Industrial VPO Catalyst Pellets. Density and compositional maps of three raschig ring-type VPO catalyst pellets. Specifically of one quadrant from the inner ring surface (left) to the outer (right). Provided cross-sectional views were obtained using scanning X-ray diffraction. Provided from left to right are maps of a pristine (i), an in-use pellet (ii), and a pellet extracted from a reactor hot spot zone (iii). Presented from top to bottom are maps showing the distribution of the main catalyst components. Scale bars are $400 \mu \mathrm{m}$. Maps belonging to a catalyst pellet share a common colour map, ranging from white to red. 
a)

(i) Pristine VPO

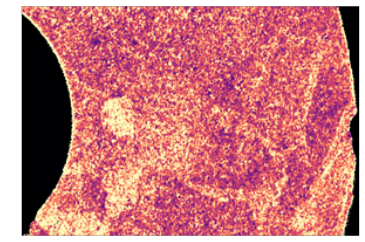

(ii) Used VPO

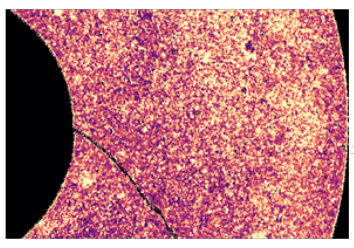

1 Intensity Ratio of (200)/(024) of (VO) ${ }_{2} \mathrm{P}_{2} \mathrm{O}_{7}$

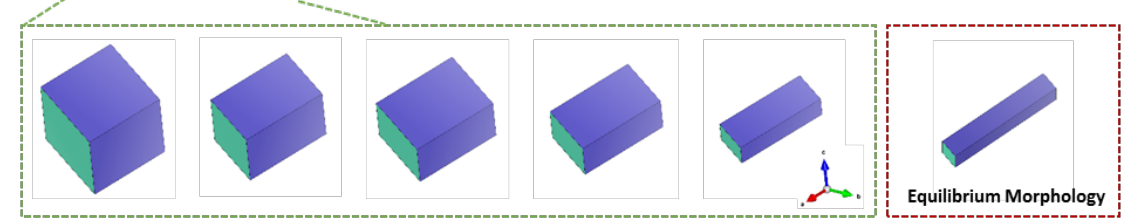

b)
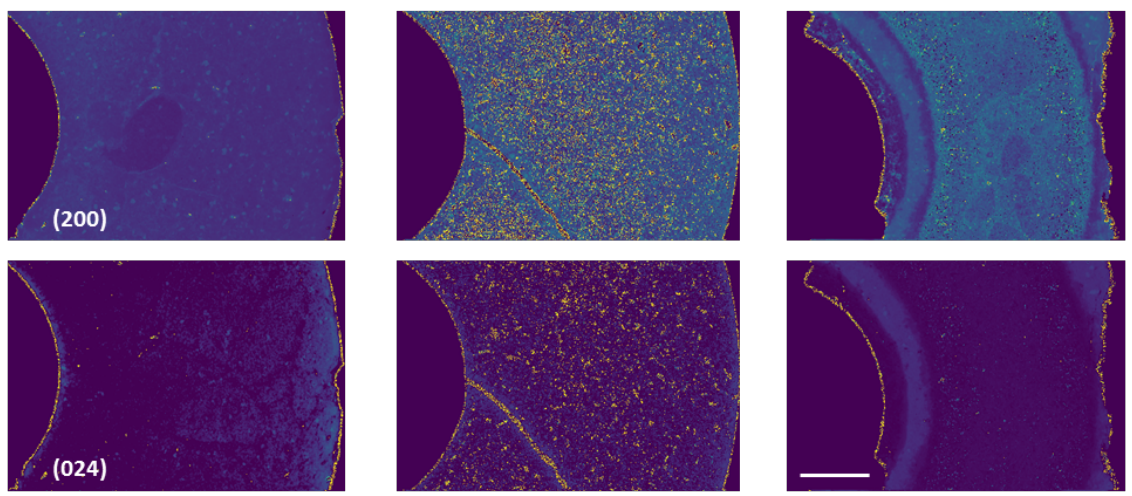

0

0.25 Micro strain, $\mu \varepsilon$, of (Vo) ${ }_{2} \mathrm{P}_{2} \mathrm{O}_{7}(\%)$

Figure 3: Microstructural Mapping of Vanadyl Pyrophosphate in Industrial VPO Catalyst Pellets. Crosssectional maps of one quadrant of three VPO catalyst pellets obtained using scanning X-ray diffraction. Provided from left to right are maps of a pristine (i), an in-use pellet (ii), and a pellet extracted from a reactor hot spot zone (iii). (a) Maps showing the local intensity ratio between the $(200) /(024)$ reflections of vanadyl pyrophosphate. Scale bar is $400 \mu \mathrm{m}$. Maps share a colour map, ranging from black to white. Furthermore, shown are a series of Wulff constructions of vanadyl pyrophosphate crystals emphasising possible morphological transitions of the scattering domains. The intensity ratio of the six most dominant reflections was considered in these Wulff constructions. (b) Reflection-specific micro strain maps of vanadyl pyrophosphate. Shown are maps for the (200) and (024) reflections. Maps share a colour map, ranging from blue to yellow. 


\section{Supporting Information:}

\section{Materials}

Pristine and industrial in-use VPO catalyst pellets, roughly $5 \mathrm{~mm}$ in diameter, produced in a fully automated and computer-controlled plant were provided by Clariant AG. The in-use pellets were sourced from an industrial fixed-bed reactor after 4 years of operation, i.e. after an overall time on the steam of 38000 hours. Specifically, they were extracted from a catalyst bed, operated in an upward gas flow configuration and at near-constant salt bath temperature. The temperature was held at $\sim 400^{\circ} \mathrm{C}$ until 16000 hours of operation before gradually increasing the temperature to $420^{\circ} \mathrm{C}$ to ensure a steady conversion rate in face of catalyst deactivation, Figure S1. A pellet from the pristine and two from the used catalyst population were examined by scanning X-ray diffraction. The two used catalysts differ from each other on the basis of their location in the fixed-bed reactor. One type was extracted from the centre of the bed, while the other was extracted from a hot spot zone reaching temperatures up to $460^{\circ} \mathrm{C}$ close to the feed stream inlet. Samples were stored in environment-isolated containers as much as possible prior to examination. The industrial VPO catalysts themselves are porous bulk type vanadyl phosphate catalysts and as such, they are predominantly composed of vanadyl pyrophosphate, $(\mathrm{VO})_{2} \mathrm{P}_{2} \mathrm{O}_{7}$, and to a lesser extent of various vanadium phosphate phases, $\mathrm{VO}_{x} \mathrm{PO}_{4}\left(\mathrm{H}_{2} \mathrm{O}\right)_{n}$. [1, 40] Furthermore, catalysts are sparsely decorated with bismuth oxide nanoparticles, Figure S3, which are added to increase catalytic activity and selectivity towards maleic anhydride.[41]

\section{General Methods}

Catalyst Composition: The population average chemical composition of the industrial VPO catalysts was determined by inductively coupled plasma atomic emission spectrometry (ICP-AES). The catalyst was dissolved in aqueous $\mathrm{H}_{2} \mathrm{SO}_{4}$ prior to the measurement. Bulk Vanadium Oxidation State: Following dissolution in aqueous $\mathrm{H}_{2} \mathrm{SO}_{4}$, the catalysts' average oxidation state was determined using redox titration. $\mathrm{KMnO}_{4}$ and $\mathrm{FeSO}_{4}$ were used as titration reagents to determine the initial amounts of $\mathrm{V}^{4+}$ and $\mathrm{V}^{5+}$ in the respective catalyst samples. The reported vanadium oxidation state in Table S1 represents the concentration average of both species. Catalytic Properties and Performance: The performance of industrial VPO catalyst samples was evaluated over the whole catalyst lifetime using a 3-channel IR sensor (butane, $\mathrm{CO}, \mathrm{CO}^{2}$ ) after scrubbing all organic acids (maleic anhydride, acetic acid, acrylic acid) and drying of the reaction gas. Porosity: Average pore size and total porosity of the pristine and used VPO catalysts were determined on a bulk-level by nitrogen physisorption and mercury intrusion porosimetry. Prior to each measurement, the sample was degassed for $10 \mathrm{~h}$. The pore diameters were calculated using the Washburn equation with a contact angle of $140^{\circ}$. The bulk- average results are given in Table S1. Electron Microscopy (EM): Scanning electron micrographs (SEM) were acquired using a Quanta 200F operated at $20 \mathrm{kV}$. The as-obtained samples were deposited on a carbon tape supported on SEM stubs. 


\section{Scanning X-ray Diffraction}

Sample Preparation: Catalyst pellets were dissected twice along the pellets' long axis to extract a single quadrat approximately $1.5 \mathrm{~mm}$ in diameter. From this quadrant, we then extracted a single thin section up to $20 \mu \mathrm{m}$ in thickness central to pellet height. Thin sections were prepared by embedding the isolated quadrant into epoxy resin and mechanical polishing. These sections were then transferred on a silicon nitride membrane. Examination of a single pellet quadrant was deemed sufficient to investigate changes given the pellets' radial symmetry.

Setup and Data Acquisition: Scanning X-ray diffraction experiments were performed at beamline ID 13 (microbeam hutch) of the European Synchrotron Radiation Facility (ESRF).[42] The photon energy was set to $13 \mathrm{keV}$ using a Si (111) channel-cut monochromator. The beam was focused to $2 \mu \mathrm{m}$ spot size using Beryllium compound refractive lenses with parabolic lens elements of $50 \mu \mathrm{m}$ radius of curvature at the apex. The sample holding membranes were aligned perpendicular to the $\mathrm{x}$-ray propagation direction using an on-axis video microscope. A beam stop was placed behind the sample to block the transmitted primary beam and to reduce the background signal. Diffraction patterns were recorded using an Eiger X 4M detector (Dectris, pixel size $75 \mu \mathrm{m}^{2}$ ), [43] covering a q-range of 1.414 to $56.232 \mathrm{~nm}^{-1}$. The sample to detector distance was calibrated using $\alpha-\mathrm{Al}_{2} \mathrm{O}_{3}$. Catalyst pellet thin sections were raster-scanned with a step size of $2 \mu \mathrm{m}$ and scanning point acquisition time of 200 milliseconds. Following the acquisition, we were first azimuthally integrated the $2 \mathrm{D}$ diffraction patterns per scanning point using the PyFAI library.[44] The obtained 1D diffraction patterns were next converted to q-space. The spatial resolution of the diffraction maps was evaluated by means of Fourier ring correlation (FRC),[45] based on intensity maps acquired away from the main diffraction peaks, i.e. at a q value of $2 \mathrm{~nm}^{-1}$, Figure $\mathrm{S} 2$. Analysis of diffraction patterns was carried out using ImageJ[46] and matlab routines. To improve the signal-to-noise ratio, we binned the diffraction maps to a pixel size of $4 \times 4 \mu \mathrm{m}^{2}$. Next, we converted the data to d-spacing allowing for a direct comparison with the literature reported diffraction patterns of common catalyst components. In figure 2 , compositional maps were created via component-specific signal integration. The two most dominant reflections for each component were considered. In figure 3, microstructural maps were obtained using the approach described in Pokroy et. al. (2006) and (2017).[38, 39] 
Supporting Figure S1: VPO Catalyst Performance over Catalyst Lifetime in an Industrial Fixed-Bed Reactor. Shown in the top panel are the catalyst productivity data of the studied catalysts over the catalyst lifetime or time on steam. Provided in the bottom panel is the corresponding reactor, i.e., Salt bath, temperature (SBT), and hot spot temperature (HST) over the catalyst lifetime.
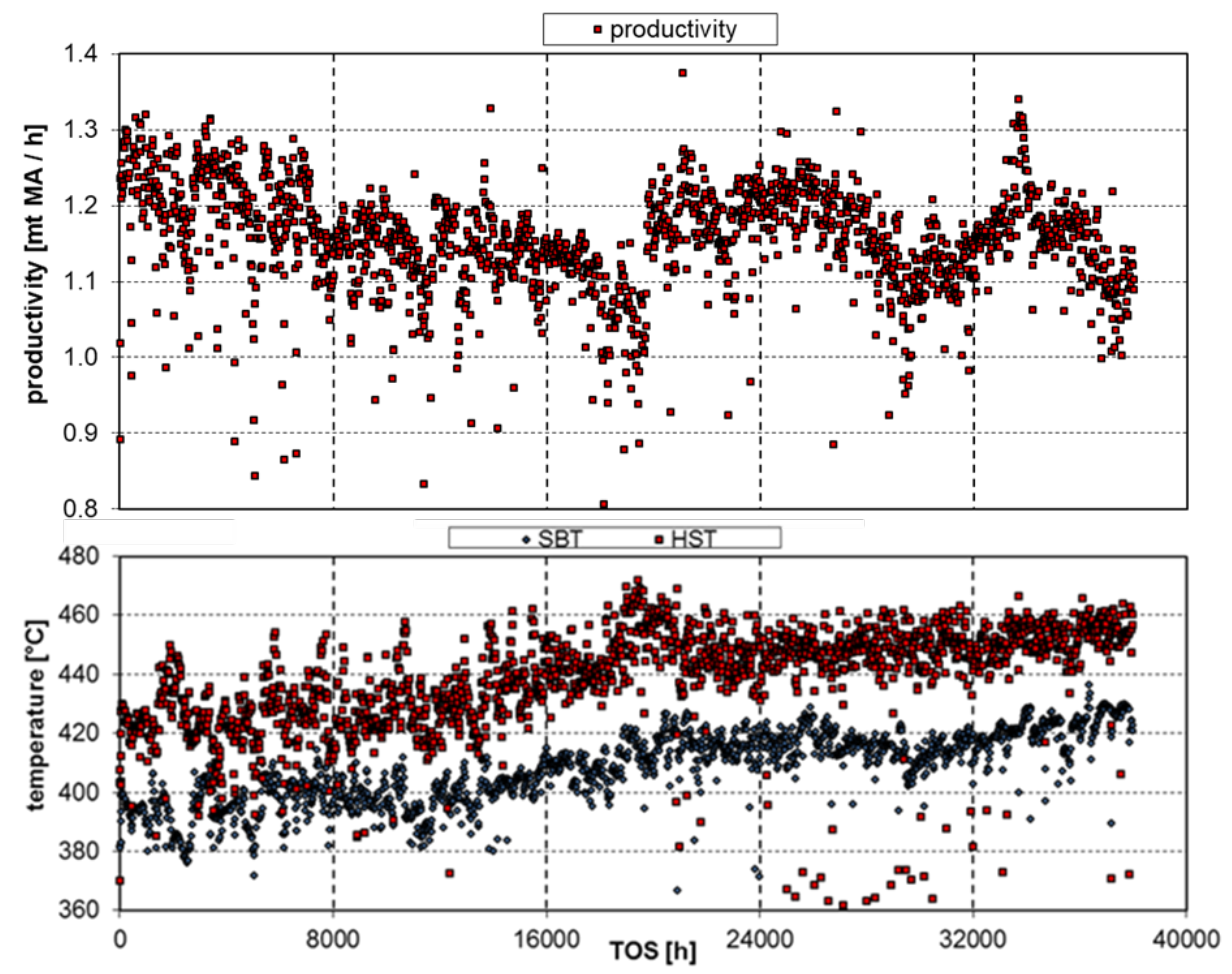
Supporting Figure S2: Fourier Ring Correlation of Scanning X-ray Diffraction Maps. Provided are FRC curves of the binned scanning X-ray powder diffraction maps shown in the main text, for the pristine and the two used VPO catalysts (The pixel size is $4 \mu \mathrm{m}$ for all samples). The pristine and the used catalysts reached a pixelsize-limited resolution using the 1-bit threshold.

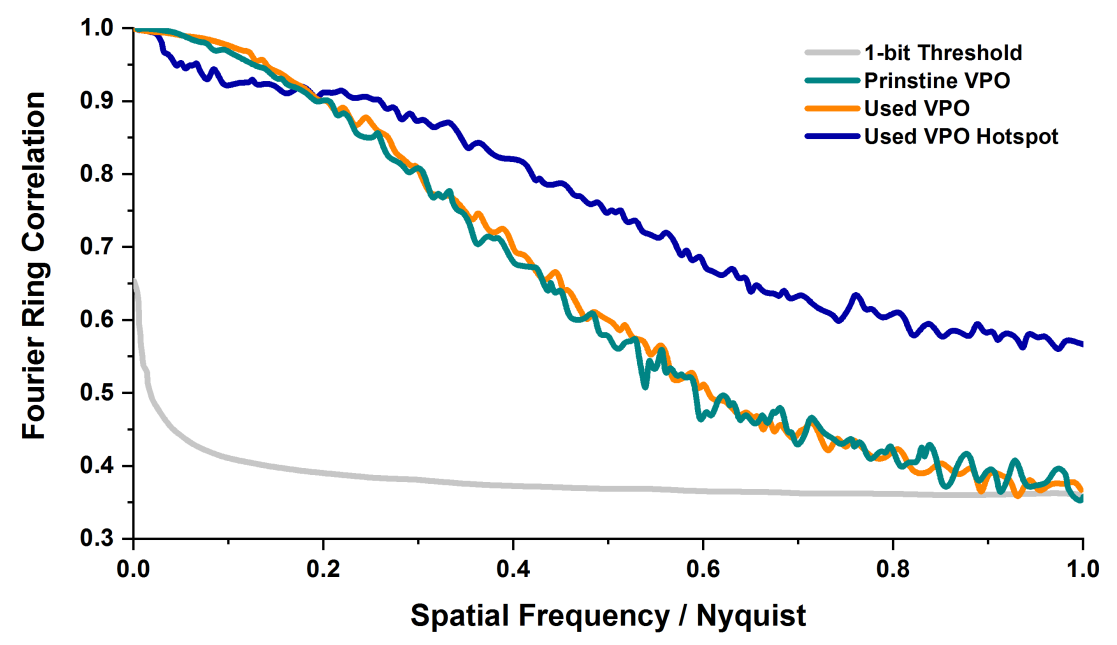


Supporting Figure 3: Scanning Electron Microscopy of Pristine and used Industrial VPO Catalysts. Micrographs of mechanically fractured catalyst pellets showing the interior of the catalyst. Micrographs were recorded with backscattered electrons at an increasing magnification of a pristine (i) and a used (ii) catalyst pellet. To note, are the changes in pellet-interior porosity and morphology with industrial use.
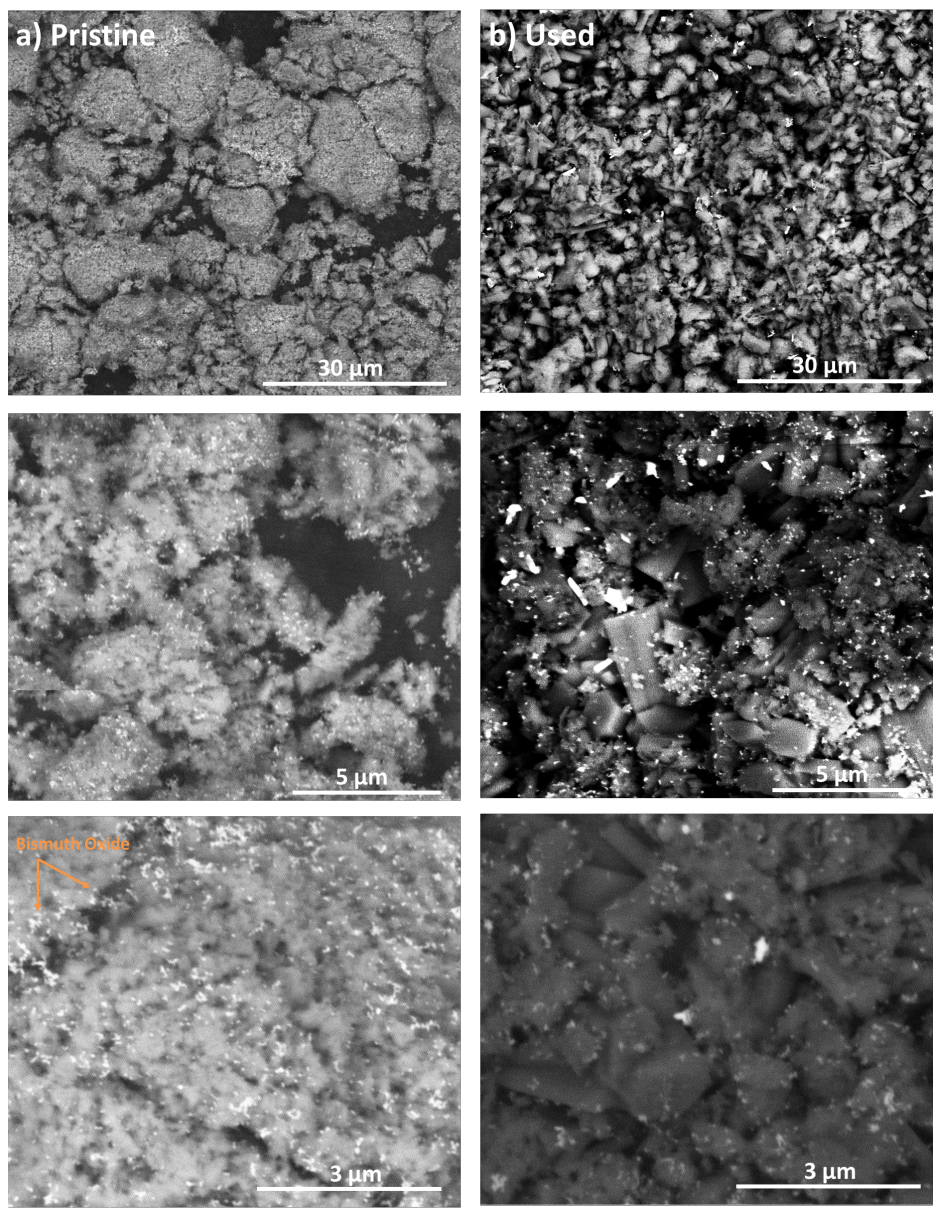
Supporting Table S1: Properties and Composition of Pristine and Used Industrial VPO Catalysts.

\begin{tabular}{|l|c|c|c|}
\hline \multicolumn{1}{|c|}{$\begin{array}{c}\text { Sample } \\
\text { Bulk Analysis }\end{array}$} & (i) Pristine & (iii) Used HS \\
\hline PN & 1.075 & 1.038 & 1.025 \\
\hline & & & \\
\hline Total Surface Area $\left[\mathrm{m}^{2} \mathrm{~g}^{-1}\right]$ & 20 & 11 & 6 \\
\hline Average Pore Diameter $[\mathrm{nm}]$ & $\sim 33$ & $\sim 65$ & $\sim 187$ \\
\hline & & & \\
\hline Mean Vanadium Oxidation State & 4.08 & $\mathbf{4 . 0 2}$ (Population Average) \\
\hline
\end{tabular}


Supporting Move S1-3: Virtual Slices Through the Scanning X-ray Diffraction Data of Industrial VPO

Catalysts. Shown are cut slice animations through the raw 1D diffraction patterns of the acquired powder X-ray diffraction micrographs of the VPO catalyst thin sections shown in the main text. Presented is the full field-ofview. 